\title{
Rural Farming Households Vulnerability to Climate Variability in Malawi: A Case of Chitekwere Area Development Programme (ADP) in Lilongwe District
}

\author{
Catherine $\mathrm{Ng}^{\prime} \mathrm{ambi}^{1}$, Joseph Dzanja ${ }^{2} \&$ Weston Mwase ${ }^{3}$ \\ ${ }^{1}$ Center for Agricultural Research \& Development, Lilongwe University of Agriculture \& Natural Resources, \\ Lilongwe, Malawi \\ ${ }^{2}$ Department of Agribusiness, Lilongwe University of Agriculture \& Natural Resources, Lilongwe, Malawi \\ ${ }^{3}$ Department of Forestry, Lilongwe University of Agriculture \& Natural Resources, Lilongwe, Malawi \\ Correspondence: Catherine Ng'ambi, Lilongwe University of Agriculture \& Natural Resources, P.O. Box 219 \\ Lilongwe, Malawi. E-mail: melodypk@yahoo.com
}

Received: February 5, 2015 Accepted: April 15, 2015 Online Published: June 15, 2015

doi:10.5539/jas.v7n7p93 URL: http://dx.doi.org/10.5539/jas.v7n7p93

\begin{abstract}
Malawi has been experiencing a variety of climatic hazards which include intense rainfall, floods, seasonal droughts, multi-year droughts, dry spells, cold spells, strong winds, thunderstorms, landslides, hailstorms, mudslides and heat waves, among many others. These hazards have been undermining the capacity of small holder households to produce various agricultural commodities. This paper therefore details the results of a study conducted in Malawi aimed at establishing the determinants of household vulnerability in rural farming households of Chitekwere Extension Planning Area (EPA) in Lilongwe District. A household survey of 217 randomly selected households was undertaken to collect primary data. Households were classified into different levels of vulnerability using a Household Vulnerability Index (HVI). In addition, a Logit model coupled with one sample t-tests, Principal Component Analysis and Sensitivity Analysis were used to characterise rural household vulnerability. The analysis yielded two vulnerability categories of low and moderate levels. The Household vulnerability cut-offs were as follows: 65-100 high vulnerability, 41-64.48 moderate vulnerability and 0-40 low vulnerability. The results showed that $7.4 \%(n=16)$ of the households were least vulnerable and $92.6 \%(n=201)$ were moderately vulnerable. The estimates of the logit model revealed that Income Generating Activities (IGA), household size, landholding size, education and access to external support were the most important factors determining household vulnerability. These factors would influence households to graduate from moderate to low vulnerability or vice versa. Principal component Analysis results showed that the proportion of maize production had the highest weight in assessing sensitivity of households due to decline of maize yield. The results have implications for the development of appropriate policies that will mitigate the negative effects of climate change in Malawi.
\end{abstract}

Keywords: climate change, climate variability, vulnerability, Malawi

\section{Introduction}

In most developing countries, households are vulnerable to climate shocks such as droughts and floods especially in economies where the majority is dependent on rain-fed agriculture for their livelihood. Household welfare is significantly not only as a direct result of these shocks, but also a consequence of the costly measures used by households to protect consumption from such shocks (Kochar, 1995).

At household level, poverty levels remain unbearably high, credit markets are usually imperfect and can only reach a minority of the population, and social safety nets are inadequate. Climate change models project that Malawi will experience a reduction in rainfall, increased frequency of droughts and an increase in temperatures by 2050 (Houghton, 2001). These changes in climate have negative implications on rural household farmers' livelihoods that are unable to cope with extreme climate events.

The agricultural sector is dominated by small-scale mixed crop-and-livestock production with very low productivity. The major factors responsible for this low productivity include: reliance on obsolete farming 
techniques; soil degradation caused by overgrazing and deforestation; poor complementary services such as extension services, credit, markets and infrastructure; and climatic factors such as drought and flood (Deressa, 2007). These factors reduce the farmers' adaptive capacity and/or increase their vulnerability to future changes, negatively affecting the performance of the already weak agricultural sector.

\subsection{Climate Trends in Malawi}

Malawi has a sub-tropical climate, which is relatively dry and strongly seasonal. The warm-wet season stretches from November to April, during which $95 \%$ of the annual precipitation takes place. The dry period is experienced between May to October (Malawi Meteorological Department, 2006). The poor communities are exposed to various types of risks natural hazards including floods, seasonal and multi-year droughts, dry and cold spells, strong winds and thunder storms. As the majority of the poor are subsistence farmers, relying on rain-fed agriculture, natural hazards continue to impact negatively on their welfare due to substantial losses of income and crops. Risks and hazards are important determinants of poverty or vulnerability due to their effect on household's livelihoods. In developing countries like Malawi, risks are higher in agriculture, fisheries and other components that constitute the livelihoods of rural populations (Adger et al., 2003).

\subsection{Climate Change and Agriculture}

In Malawi, agriculture plays a significant role in the social and economic development of the country. It contributes about 39 percent to the gross domestic product (GDP) while up to 90 per cent of the labour force is employed in agriculture and related sectors (GoM, 2009). In Malawi, agriculture is directly affected by climate change and also contributes significantly to greenhouse gas emissions. Agriculture remains the only major source of income in terms of employment and foreign exchange in Malawi (FAO, 2007; Deloitte, 2011). Climate variability has been significantly destructive and disruptive to crops growing communities (Action Aid, 2008) threatening food security in the areas (World Bank, 2010; NSO, 2008). Furthermore, as most rural people depend on agriculture for subsistence, unreliability of rainfall causes losses in incomes, and increased general vulnerability to food security (GoM, 1998). Recently Malawi has been experiencing significant variations in weather patterns. The Vulnerability and Adaptation Assessment Report of 2001 indicates that Malawi is experiencing a variety of climatic hazards, which include intense rainfall, floods, seasonal droughts, multi-year droughts, dry spells, cold spells, strong winds, thunderstorms, landslides, hailstorms, mudslides and heat waves, among many others. The floods related to climate variability that afflicted some of the SADC countries including Malawi in 2000, and the repeat performance in 2001 and 2015 were associated with climate change by some experts with climate change (Wamukonya \& Rukato, 2001).

\subsection{Understanding Household Vulnerability}

Practitioners from various disciplines use the term vulnerability differently (Makoka \& Kaplan, 2005). This has led to diverse methods of measuring it. In general, vulnerability refers to the relationship between poverty and risk, including efforts made to mitigate or manage the risk. A household is regarded as vulnerable if there is future potential loss of welfare. The degree of vulnerability depends upon the capacity of that household to respond to the risk. This implies that measurement of vulnerability depends on the time horizon, implying that households may be vulnerable at certain time of the year. Vulnerability is an ex-ante measure of well being whereas poverty is an ex-post measure of well-being or lack thereof (Chaudhuri, 2003). Kanbur and Squire (1999) observe that economists often use money-metric terms to define vulnerability. Other scholars define vulnerability using the asset base and highlight that it is closely related to asset ownership. The few tangible and intangible assets a household owns, the more vulnerable it becomes and vice versa. Siegel and Alwang (1997) describe tangible assets as land, labour, capital, savings (natural, human, physical and financial assets) while intangible assets include social, institutional and political relationships, physical and social infrastructure and location. Different assets can be used to manage various possible risks.

\subsection{Measuring Vulnerability to Climate Change in Malawi}

The severe impacts of climate variability, and especially drought, on households in Malawi became evident in 2001 and 2002. A combination of local floods and a regional drought led to a 32 per cent drop in the production of the local staple crop, maize, and estimates of deaths due to starvation and hunger related diseases range from 300 to 3000 in 2002 (Devereux, 2002). In order to investigate the more disaggregated impacts of climate change in Malawi it is necessary to take into account the characteristics of the production system as well as households. The rainy season normally takes place between November and April. At the beginning of the rainy season the main planting takes place, which also means that this is the peak season for labour demand. Most small-scale farmers in Malawi sell some casual labour, known as Ganyu labour during this season, in addition to planting on their own plots. The rainy season is also known as the hunger season, since the stocks from last year's harvest are 
likely to be reduced by this time, and market maize prices increase. The poor households therefore depend on being able to sell their labour to afford buying food. If the demand for labour is low due to unfavourable conditions, for instance due to a drought or flood, this could have serious impacts on poor households. In addition to reduced yields on their own plots, they have to deal with high market prices for food and lack of income from Ganyu labour.

\subsection{Measures of Vulnerability}

Between 2004 and 2007 the Food Agriculture and Natural Resources Policy Network (FANRPAN) developed a statistical index for measuring vulnerability - the Household Vulnerability Index (HVI). The index categorizes a household by assessing "external" vulnerability that is introduced by shocks and "internal" vulnerability or inability of such a household to withstand shocks, and then classifies the household into three levels of low, medium and high vulnerability depending on the household's ability to prevail. The HVI tool uses five capital assets (natural, social, physical, human and financial). Households are classified into three categories based on their statistical HVI score (between 0-100). The HVI has both internal and external vulnerability components employed. External vulnerability is assessed separately and used to adjust weights on the household's access to the five capitals. Each of the 15 dimensions measures internal vulnerability.

According to Sibanda et al. (2008) the Household Vulnerability Index (HVI) approach is a measure that was developed to measure vulnerability of households and communities to the impacts of diseases and shocks such as HIV and AIDS and poverty. The HVI approach achieved this by comparing wealth or assets that are available to a household, and classifies the households according to three levels of vulnerability to the particular issue. In order to be able to address vulnerability effectively, it needs to be measured so that areas of highest priority can be identified and this equity approach to vulnerability is critical for sustainable development in general.

\section{Methodology}

\subsection{Study Design}

The study involved both quantitative and qualitative data assessment. The qualitative approach was adopted because it sought to build a deeper understanding of household vulnerability to climate change and its related dimensions. In addition, a quantitative approach was adopted with regard to computing the different levels of vulnerability.

\subsection{Description of the Study Area}

The study was carried out in Chitekwere Extension Planning Area (EPA) in Lilongwe Malawi. Malawi is divided into three administrative regions; Northern, Central and Southern. Lilongwe district is in the Central region of Malawi. The Lilongwe plain is located on the mid altitude plateau of central Africa and represents one of the most fertile agro-ecological zones in Malawi that stretches to Dedza, Mchinji, Dowa and Kasungu districts. Lilongwe district has generally dark red clay or sandy clay soils suitable for growing maize, tobacco, groundnuts, beans, Irish potato, sweet potato, soya beans and cassava do well in this type of climate. Chitekwere EPA is located $70 \mathrm{~km}$ South East of Lilongwe city (Figure 1). It is under Traditional Authority (TA) Chitekwere, in Nkhoma Area Development Program (ADP). The goal of the project was to apply the HVI to improve development projects that could be designed targeting households depending on their level of vulnerability and socioeconomic characteristics. The study was implemented by Food, Agriculture and Natural Resources Policy Network (FANRPAN) in conjunction with International Development Research Centre (IDRC) of Canada. A similar project was implemented in two countries namely Lesotho and Swaziland. 


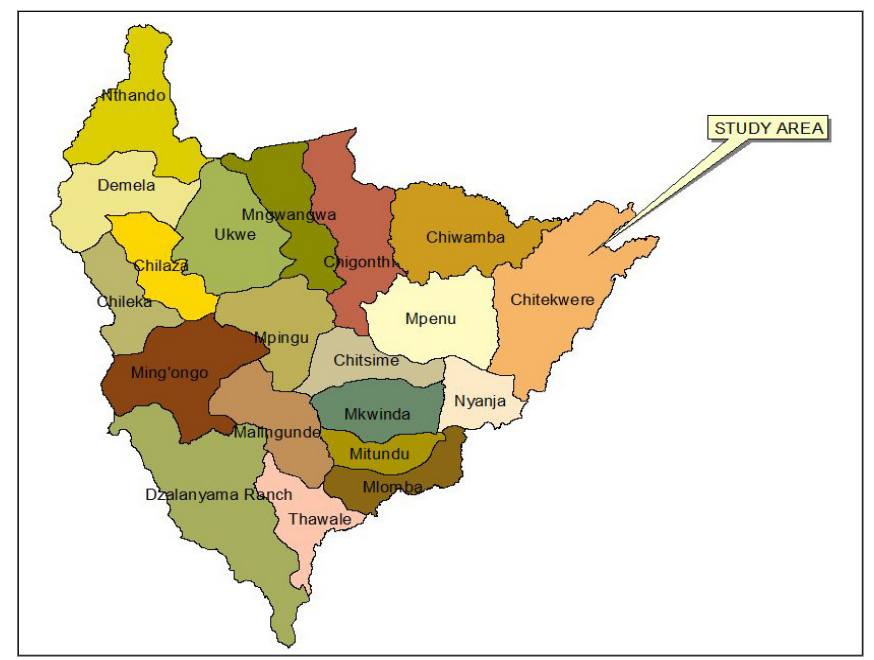

Figure 1. Map of Lilongwe District showing Chitekwere Extension Planning Area

\subsection{Sampling Design}

Sampling is a fundamental part of a quality survey to ensure representation of the survey population. A Multi-Stage Sampling method was used to select a representative sample of 217 households. The study purposively targeted Lilongwe District in Nkhoma ADP basing on the agreement between Food, Agriculture and Natural Resource Policy Analysis Network (FANRPAN) and World Vision Malawi. Three Group Village Headmen (GVH) Chipsye, Mtambwa and Khuwi were purposively selected because it is where World Vision is doing a pass on intervention. The sample frame was collected from Lilongwe (Nkhoma ADP - World Vision office). Households in the three group $(\mathrm{GVH})$ village headmen were randomly selected. Probability proportional to size (PPS) was employed to determine the total number of households to be sampled in each of the three GVHs for representativeness of the sample size as in Table1.

Table 1. Village headmen and sampled villages

\begin{tabular}{lll}
\hline Group Village Headperson & Village & Household Number \\
\hline Khuwi & Mavule & 23 \\
& Kawale & 27 \\
& Matama & 10 \\
\hline Chipsye & Kaphiri & 37 \\
& Mponda & 24 \\
& Kachepa & 24 \\
& Mphinzi & 17 \\
\hline Mtambwa & Njobvuyalema & 17 \\
& Mtambwa & 27 \\
& Nthumbira & 11 \\
\hline Total households & & 217 \\
\hline
\end{tabular}

Note. These three GVHs have a total of 527 households and a total of 10 villages.

\subsection{Data Collection}

Primary data were collected through personal interviews from 217 sampled households using an interview questionnaire. The data were collected between December 2012 and January 2013.

\subsection{Data Analysis}

Descriptive statistics such as percentages and frequencies were used to analyse the data. The Statistical Package 
for Social Sciences (SPSS) version 20 and Microsoft Excel were used to analyse the data. The factors affecting vulnerability were analysed using multinomial logistic regression. The results showed that in high vulnerability category was only one household, as a result was put in moderate vulnerability category for easy analysis of results.

\subsection{Analytical Framework}

To establish the vulnerability of the households, the household vulnerability index was calculated. The framework was based on the fact that capitals change due to external shocks or disasters that they are exposed to at any time. When a disaster occurs, it impacts directly on the capital assets thereby reducing the ability of a household to cope. The fuzzy set approach was used to calculate the HVI as follows:

- $\quad$ One can state that for the population $N$ made up of $\mathrm{n}$ households i.e. $(N=\{h h 1, h h 2, h h 3, \ldots h h n\}, \mathrm{V}$ is a subset of $v$ households that have some degree of vulnerability, hence having internal vulnerability. Thus $v \leq n$ and $v=0$ implies that there are no vulnerable households, and $v=n$ implies that all households are vulnerable.

- One can also break down the vulnerability $X$ into $m$ specific dimensions of impact, and give a corresponding weight $(w i, i=1, \ldots m)$ to each dimension. The weights can be predetermined, or developed using an appropriate function. For the generalized HVI model, the weights correspond to the external component of vulnerability.

- The vulnerability of any given household hhi $i=1 \ldots n$ to the $j t h j=1, \ldots m$ dimension of impact can be expressed as $X_{i j}$, and set to take values between 0 and 1 such that $0=$ no impact and 1 full impact. Thus each $X_{i j}$ denotes the degree of vulnerability of household $i$ to the $j$ th dimension of impact, and $X_{i j w i}$ will be the corresponding weighted vulnerability.

- The sum of the weighted vulnerabilities across all dimensions will give the particular household's total vulnerability $V h h i$, that is:

$$
\sum_{j=1}^{m} X_{w j} / \sum_{j=1}^{m} w_{j}=V h h_{i}
$$

Which estimated that the occurrence of an event had a probability value ranging between 0 and 1 . This implies that the $H V I$ ranges from 0 to 100 after transforming the respective probabilities to percentages. The assumption is that households exist in a fairly homogenous context, and the sum of the weights is made such that:

$$
\sum_{j=1}^{m} w_{j}=100
$$

Where 0 represents no vulnerability while 100 represents full impact.

Household Vulnerability characteristics with respect to capital assets endowments were determined using the Logit Model. Logit Model was used because of the binary nature of the dependent variable HVI which takes on the value 1 for "low vulnerability" and 0 for "moderate vulnerability". The probability of a household to fall under low vulnerability category is given by $H V I=1$ which is defined as $\pi=P(H V I=1)$. On the other hand, a household is regarded as falling under moderate vulnerability if its probability is given by $1-\pi=P(H V I=0)$. It is assumed in logit modelling that there is a set of independent variables $X 1, \ldots X n$, that affects HVI which in essence provides profound information in predicting HVI as given below,

$\log _{e}=\left[\frac{P\left(H V I=1 ; X_{1}, \ldots X_{n}\right)}{1-P\left(Y=1 ; X_{1}, \ldots X_{n}\right)}\right]=\log _{e}=\left[\frac{\pi}{1-\pi}\right]=\beta_{0}+\beta_{1} X_{1}+\beta_{2} X_{2}+\beta_{3} X_{3}+\beta_{4} X_{4}+\ldots+\beta_{n} X_{n}+e_{i} \quad$ HVI $[0,1]$

Where:

$H V I$ : Dependent variable; $\beta_{0}$ : Intercept parameter $B ; B_{i j}$ : estimation parameters of the model; $X_{1}, \ldots X_{n}$ : Vector of independent variables which were used in the analysis such as external support, access to extension services, income generating activities participation, marital status, household size, land size, age and education.

Furthermore, one Principal Component Analysis (PCA) was used to determine the weights of variables in order to construct index for sensitivity to maize yield decline. The variables used were: maize production/yield, reduced number of meals, agricultural extension services, land size, and use of less or no fertilizer/manure Table 2 illustrates that the proportion of maize production had the higher weight in assessing how sensitive households are to a decline in crop yields. 
Table 2. Principal component analysis - variable weights

\begin{tabular}{ll}
\hline Variable & Proportion \\
\hline Maize production/yield & 0.34 \\
Reduced number of meals & 0.24 \\
Agricultural Extension Services & 0.17 \\
Land size & 0.15 \\
Use of less or no Fertilizer/manure & 0.10 \\
Total & 1.00 \\
\hline
\end{tabular}

Sensitivity index was computed in the current study to measure the impact a household will experience due to decline in maize yields as in Table 3.

Table 3. Methods used in computing the sensitivity index

\begin{tabular}{|c|c|c|c|c|}
\hline Variable & Weight & Assumption & Description of the variable & Calculation \\
\hline $\begin{array}{l}\text { Maize } \\
\text { production/yield }\end{array}$ & 0.34 & $\begin{array}{l}\text { Households that yield/produce less maize } \\
\text { are vulnerable to maize decline due to } \\
\text { climate change. }\end{array}$ & $\begin{array}{l}\text { Per capita staple cereal output (X). What is } \\
\text { the total household size (Y)? How many } \\
\text { Kgs of Maize were harvested (Z)? What is } \\
\text { the staple cereal requirement for an } \\
\text { individual household member (S)? }\end{array}$ & $\mathrm{X}=\mathrm{Z} /(\mathrm{Y} * \mathrm{~S})$ \\
\hline
\end{tabular}

Reduced number of meals by adults and children

Access to Agricultural Extension (crops)

Land size 0.15

Households that have small size of land

Use of less or no Fertilizer/manure or do not fully utilize their existing land are more vulnerable to declines in maize

yields due to climate change.

Households take less meals per day due
to inadequate food availability, are more
vulnerable to declines in maize yields.

Households that have limited access to extension services are vulnerable to declines in Maize yields caused by climate change into the future.

Households that do not fertilize their land will be more vulnerable to declines in Maize yields caused by climate change into the future.
Number of meals taken daily by adults(X) where $\mathrm{Zi}=0,1,2,3$ or more is the number of meals taken.

Extension services access $(\mathrm{X}): \mathrm{Yi}=1$ if household has access to livestock extension services; 1 if household has access to crop extension services; 0 otherwise.

Proportion of land is available but not used $\mathrm{X}=1-\mathrm{E} / \mathrm{F}$ due to illness or death $(\mathrm{X})$ where size of land not utilized (E), and total land available for cultivation $(\mathrm{F})$.

Proportion $\mathrm{X}$ of the household field that is $\mathrm{X}=\mathrm{A} / \mathrm{B}$ fertilized by natural means, where $\mathrm{A}$ is the land size fertilised by natural means and $\mathrm{B}$ is the total land size.

\section{Results and Discussion}

\subsection{Household Vulnerability in Chitekwere EPA}

To address the question of vulnerability to external shocks in Chitekwere the Household Vulnerability Index was used to establish the vulnerability status of the studied households. According to FANRPAN (2011), through the HVI, the households are classified into three categories: lowly vulnerable, which are households that are in a vulnerable situation, but can still cope; moderately vulnerable households, those that need urgent but temporary assistance in case of a shock and the highly vulnerable households are those that are almost at a point of no return. After using the HVI on characterizing the households in Chitekwere only two categories were found that is low and moderate vulnerable households. There was only one household who was in high vulnerability and 
was not showing any significance using the multinomial logistic model as a result was added to moderate vulnerability category. The results in table 4 below, show that about $92.6 \%$ of the households were lowly vulnerable and $7.4 \%$ were moderately vulnerable. The description of the dependant variable used in the logit regression model show that lowly vulnerable households have an HVI ranging from 0 to 40 , moderately vulnerable households have an HVI of 41 to 64.48 and highly vulnerable households have an HVI of 65 to 100 as in table 4 below:

Table 4. Description of the dependent variable for the logit model

\begin{tabular}{|c|c|c|c|c|}
\hline Vulnerability Category & HVI_Range & Situation & Freq. & $\%$ \\
\hline $\begin{array}{l}\text { High } \\
\text { Vulnerability }\end{array}$ & $65-100$ & $\begin{array}{l}\text { Emergency level household-the equivalent of an intensive care } \\
\text { situation-could be resuscitated only with the best possible expertise. }\end{array}$ & 0 & 0.0 \\
\hline $\begin{array}{l}\text { Moderate } \\
\text { Vulnerability }\end{array}$ & $41-64.48$ & $\begin{array}{l}\text { When hit hard by a shock, the household needs urgent but temporary } \\
\text { external assistance for it to recover. }\end{array}$ & 201 & 92.6 \\
\hline $\begin{array}{l}\text { Low } \\
\text { Vulnerability }\end{array}$ & $0-40$ & $\begin{array}{l}\text { Coping household-household in a vulnerable situation but still able } \\
\text { to cope. }\end{array}$ & 16 & 7.4 \\
\hline Total & & & 217 & 100 \\
\hline
\end{tabular}

Table 5. Logit model

\begin{tabular}{llll}
\hline Variable & Coefficient & Standard Error & P-value \\
\hline Education & 2.73 & 1.27 & $0.031^{* *}$ \\
Age (Years) & 0.072 & .040 & $0.072^{*}$ \\
Access to agricultural extension & 0.55 & 1.04 & 0.595 \\
Total land size (ha) & 2.52 & 1.11 & $0.024^{* *}$ \\
Household size (Number of persons) & -0.46 & .237 & $0.051^{*}$ \\
Marital status & 2.13 & 1.02 & $0.036^{* *}$ \\
IGA participation & 3.31 & 1.16 & $0.004^{* * *}$ \\
Access to external support & 2.20 & 1.06 & $0.038^{* *}$ \\
Sex & 0.69 & 1.41 & 0.625 \\
Constant & -4.58 & & \\
Sample size & 217 & & \\
Pseudo R2 & 0.5325 & & \\
LR Chi2 & 48.29 & &
\end{tabular}

Note. ${ }^{*}$ denotes significance at 0.10 level; ${ }^{* *}$ denotes significance at 0.05 level; $* * *$ denotes significance at 0.01 level.

\subsection{Factors Affecting Households Vulnerability}

According to Inayatullah et al. (2012), a vector of independent variables such as number of employed members of the household, index of livestock holding and per capita income of the household significantly affects rural livelihood. The results exhibited a significant $\mathrm{p}$-value $(\mathrm{p} \leq 0.10, \leq 0.01, \leq 0.05)$ for household head education, landholding size, marital status, participation in income generating activities, access to external support and household size entailing the relevance of the underscored factors for households to shift from moderate to low vulnerability category. Contrary to the study findings of Nkonde et al. (2013) the odds ratio for education (2.73) means that, a unit increase in the level of education increases the probability for a household to graduate from moderate to low vulnerability by $173 \%\{(2.73-1) \times 100\}$. Increasing the number of years of the household head in the area was found to be positively influencing the household's shift from moderate to low vulnerability by 93 $\%\{(1-0.072) \times 100\}$. 
It was established that about $60 \%$ of people at Chitekwere EPA attain their livelihood through subsistence farming, the results indicated that land holding size positively affects vulnerability. Thus increasing the size of the land by a hectare, increases probability of a household to move from moderate to low vulnerability by $152 \%$ $\{(2.52-1) \times 100\}$. Similarly, increasing participation in Income Generating Activities (IGAs) increases the chance of a household graduating from moderate to low vulnerability category by $231 \%\{(3.31-1) \times 100\}$.

Household size retained a statistically significant negative sign $(-0.46)$ entailing that increase in the number of household members decreases the probability of a household to move from moderate to low vulnerability category if the additional members are non productive by $57 \%\{(0.43-1) \times 100\}$. A unit increase in the access to external support would increase the probability of a household shifting from moderate vulnerability to low vulnerability by $120 \%\{(2.20-1) \times 100\}$.

Further than that, access to extension services and household sex, were found to be insignificant. It is unexpected to find access to extension services insignificant because of adoption of coping strategies relevant to preventing reduction of the impact of drought. However, this has been the case because Chitekwere EPA has less government extension workers who rarely visit farmers in this remote area, suggesting that the constraint of low access to extension services was cutting across both low and moderate vulnerable groups. The results further showed that education positively influenced vulnerability status of the households. For one unit increase in literacy, there would be 1.267381 increased in log odds of HVI. That is, one unit increase in literacy (moving from illiterate to literate) would increase the likelihood of the household being vulnerably low. The majority of household's especially male headed (77.8\%) households had attended up to senior primary (standard 6-8) and $(36.8 \%)$ attained some secondary school. On the other hand female headed houses $(63.2 \%)$ had some secondary school education and $(22.2 \%)$ had completed primary school education. Illiterate level for both households is the same.

The education level of a household head and household members positively influences the understanding of management practices and adoption of new agricultural technologies. According to Kataria (2011) education has a desirable controlling influence over development of the rural individual, family, community and society that leads to reduced poverty and controlled unemployment. Functions of education include imparting social change, making rural people aware about their rights, improving individual standard of living, providing employment and income opportunities to rural people among other things. Based on the value of education as described by Kataria (2011), the situation of illiterate head of households significantly limits opportunities for households to gain employment and access to sustainable income opportunities.

Thus, it can be concluded that education and family composition were important contributors to economic capability and that the higher the level of education of the household the lower the vulnerability and better understanding of the management practices and adoption of new agricultural technologies hence food secure in the times of climate change.

\section{Conclusion}

The study categorized the households into two categories of moderate and low vulnerability. There were no households in high vulnerability category. The study also revealed that land holding size to both moderate and low vulnerable households was slightly the same (2.22 and 2.19 acres) respectively, this is in agreement with integrated household survey report (2012) which states that the average land size in Malawi is about 1.9 acres but ( 2 acres) in rural areas. However, low vulnerable households have more access to farm inputs like fertilizer and manure and their maize output is higher than those in moderate vulnerability category. This implies that moderate vulnerability households are resource poor and will be food insecure and adversely affected by climate change hence will need emergency external support but for a short time.

Furthermore the results revealed that household size, education of the household head, land holding size, participation in income generating activities, access to external support and marital status were significant factors in influencing household graduation from moderate to low vulnerability category. Additionally, the results revealed that only $4.5 \%$ of households in Chitekwere have functional bank accounts, whilst $30 \%$ of households are members of savings credit scheme and $35.5 \%$ receive family financial support. This entails that financial asset is the main determinant of household vulnerability as it affects their access to agricultural inputs such as fertilizer, hybrid seeds and food in times of shocks.

Access to social assets such as access to external support and access to extension services in Chitekwere EPA is another valuable determinant of household vulnerability. Increasing agricultural production by area expansion in Malawi is not a viable option because of land fragmentation emanating from population density. It is therefore imperative to intensify in productivity through enhancing technologies such as high yielding varieties, fertilizer 
application, and novel methods of faming among others. These can only come from extension service officers who at the time of the study were not adequately available whereas only $15.2 \%$ (33 out of 217) households had an access to extension services. On the other hand, access to external support significantly increases probability of household shifting from moderate to low vulnerability by $120 \%$. Nevertheless, their external support base is low hence are prone to external and internal shocks. The results indicated that the reduction in maize yields due to climate variability will decrease the moderately vulnerable households. It is estimated that 29.85 percent of households in Chitekwere will move from the moderate level of vulnerability to high level vulnerability. This indicates that these households will be adversely affected by climate change and thus making them chronically poor due to food insecurity. One of the factors that caused the current levels of vulnerability is lack of access to extension services and resources such as fertilizer and manure to dress their crops. As such government should come up with interventions that should be based according to the vulnerability level of the households and that the interventions should be specific such as provision of farm inputs (fertiliser and seed) since the results indicate that the households apply little fertilizer and manure in their crops.. The majority of households in Chitekwere EPA have inadequate access to financial services due to lack of adequate capital resources which can be turned into money; as such government should come up with appropriate intervention policies such as savings credit schemes, soft loans from commercial banks that will create an enabling environment for the households to access these financial services.

\section{Acknowledgements}

The authors acknowledge the financial support by Food Agriculture and Natural Resources Policy Network (FANRPAN) to support Catherine Ng'ambi to conduct this research as part of her Master of Science research work. Special recognition should go to staff of World Vision Malawi and all the households in Chitekwere Extension Planning Area in Malawi for providing information during field interviews.

\section{References}

Adger, W. N. (1999). Social vulnerability to climate change and extremes in coastal Vietnam. World Development , 27(2), 249-269. http://dx.doi.org/10.1016/S0305-750X(98)00136-3

Alwang, J. S. (2001). Vulnerability: A view from different discipline. Social Protection Discussion Paper Series No. 0115. World Bank, Social Protection Unit, Washington D.C.

Chaudhuri, S. (2003). Assessing vulnerability to poverty: Concepts, empirical methods and illustrative examples. Columbia University, Department of Economics.

Deressa, T. (2007). Measuring the economic impact of climate change on Ethiopian agriculture.

Devereux, S. (2008). World Vision Cash Transfers Impact Evaluation Report - Lesotho Project 2008. World Vision International.

Food and Agriculture Organization. (2001). Targeting for Nutrition Improvement. Resources for advancing nutritional well-being. FAO, Rome.

Houghton, J. D. (2001). Climate Change 2001: The Scientific Basis. Intergovernmental Panel on Climate Change. Cambridge University Press, Cambridge, UK, and New York. http://dx.doi.org/10.1023/A:1005658316062

Inayatullah, J., Munir, K. K., Khan, M. A., Shakeel, H., \& Tariq, R. (2012). Factors affecting rural livelihood choices in Northwest Pakistan. Sarhad J. Agric., 28(4), 681-688.

Kanbur, R. (1999). The Evolution of Thinking about Poverty: Exploring the Interactions. Retrieved from http://www.worldbank.org/poverty/wdrpoverty/evolut.htm

Kataria, M. (2011). Role of education in rural development: With regard to problems and suggestions. International Journal of Research in Information Technology and Management, 1(4).

Kochar, A. (1995). Explaining Household Vulnerability to Idiosyncratic Income Shocks. American Economic Review Papers and Proceedings.

Makoka, D., \& Kaplan, M. (2005). Poverty and Vulnerability an interdisciplinary approach. Retrieved from http://mpra.ub.uni-muenchen.de/6964

Malawi Government. (2002). Malawi poverty and vulnerability assessment: Investing in our future (Volume II, June draft for discussion). Republic of Malawi and World Bank, Lilongwe. Retrieved from http://www.aec.msu.edu/fs2/mgt/caadp/malawi_pva_draft_052606_fina

Malawi Government. (2002). Vulnerability and Adaptation Assessment Report of 2002. 
National Statistical Office. (2012). Integrated Household Survey 3: Household socio-economic characteristics. Zomba, Malawi.

Nkondze, M. S., Masuku, M., \& Manyatsi, A. (2013). Factors Affecting Households Vulnerability to Climate Change in Swaziland: A Case of Mpolonjeni Area Development Programme. Journal of Agricultural Science, 5(10), 108-122. http://dx.doi.org/10.5539/jas.v5n10p108

Seigel, P. B., \& Alwang, J. (1997). Seeking guidelines for poverty reduction in rural Zambia. World Development, 24(11).

Sibanda, L. (2008). Using the HVI to improve programme design and targeting in Lesotho Swaziland and Zimbabwe. A proposal submitted to World Vision.

Wamukonya, N. A. R. (2001). Climate change implications for Southern Africa: A gendered perspective. Southern African Gender and Energy Network (SAGEN).

\section{Copyrights}

Copyright for this article is retained by the author(s), with first publication rights granted to the journal.

This is an open-access article distributed under the terms and conditions of the Creative Commons Attribution license (http://creativecommons.org/licenses/by/3.0/). 